\title{
Factors Affecting Clothing Design for Autistic Children: A Study of A Sustainable Development Brand Kiddie Pal in Jakarta
}

\author{
J O Oetojo \\ Fashion Design Program, Product Design Department, Universitas Bina Nusantara, Jakarta, \\ Indonesia \\ joetojo@binus.edu
}

\begin{abstract}
There are about one million autistic children in Indonesia. Based on statistics, one out of sixty-eight children are born with autism worldwide. Getting dressed can be more challenging, based on the fact that 83 percent of children with autism have problems with theirmotor skills, especially inputting their clothes on independently. This study presents the main aspects involved in designing fashion clothing specifically created to find solutions to help children with autism in brand Kiddie Pal. Kiddie Pal runs a business based on socially responsible business practices where it adopts and implements business practices aimed at improving the quality children with autism. The research methodology utilized a qualitative method through in-depth interviews and observations using a sample collection for autistic children from Kiddie Pal and gathered inputs from experts. Clothes specially designed for children with autism should offer the easiest way to wear, feel comfortable, be safe, and feel self-reliant. In accordance with the desire to have an autistic viewpoint, the clothes are expected to offer psychological benefits and help improve the organization of sensory and social integration with the community. Using cotton material and seamless construction, selected water-based prints, no tags, less trimmings, flexible front and back clothing pieces, and a smart opening solution are answers to the problems faced by autistic children in their dressing. The design factors have to consider the motoric limitations, both psychological and social. In addition, a purpose of this study was to establish guideline recommendations for creating and designing clothing for children with autism that can support the sustainable development.
\end{abstract}

Keywords: Autistic, Kiddie Pal, Clothing For Children

\section{INTRODUCTION}

Having normal and healthy children is everybody's dream, especially for the parents. Factors such as food, family condition, illness can affect the growth of the children. There are approximately one million Indonesian people with autism. According to Autism Science Foundation, Autism is a brain-based disorder characterized by social-communication challenges and restricted repetitive behaviours activities, and interests [1]. 
Around 83 percent of children with autism have motor skill problems based on the research done from Washington University School of Medicine in St. Louis [2]. Autism is known as Autistic Spectrum Disorder (ASD), is a developmental disability in children. Symptoms typically appear before the age of two years. It is an illness condition, in which the brain cannot function properly. It affects the ability to communicate, motor skills, sensory functions, social interactions, and behaviour. The National Autistic Society revealed that autism is a life long developmental disability that can be improved but not cured [3]. Children with autism also experience unusual reactions to sound, smell, taste, sight, andfeel.They are affected by colours and touch because they are sensitive and often have average or above-average intelligence [4].

Clothing plays an important role in everyone'slife, including children with autism. It is an important basic physiological need, providing comfort and protection again stun wanted external factors. Clothing becomes more important for autistic children to give thema better quality of life through independence, security, and comfort by minimizing the tough part of garment operations, such as zippers, buttons, and closing openings. Putting on clothes for some children can be easy and fast, but for autistic children, getting dressed will take a lot of time. Based on some facts gathered from the parents of autistic children, they have to help their children inputting on their clothes. Up to 90 percent of children with autisms how sensory problems, fixatingon or avoiding certain smells, sound sortextures. Getting dressed in children with autism will take a longer time, they feel very disturbed if the clothes are too attached to the body or have a detail that makes them uncomfortable.

This case study examined children's fashion brand that focuses on autistic children's apparel in Jakarta name Kiddie Pal. The aim of creating this brand was to design adaptive clothing that is able to help autistic children have an easier time to get dressed. Kiddie Pal runs a business based on socially responsible business practices and aimed at improving the quality children with autism. Kiddie Pal does not utilize the zippers, tags, and trimmings that could challenge autistic children. Instead, Kiddie Pal creates front and backwards tops and bottoms, so that wherever they put the clothes on, they will work, look great, fit well, and be comfortable.

The objective of this research is to give recommendations or guidelines to parents and designers in creating a solution to help kids with autism get dressed independently on their own and find elements that can help them to dress feasibly, comfortably, confidently, and stylishly without any problems, frustrations ,or hassles, so that it can help improve the quality of theirlives. If children with autism do activities out side the home, they should be given protection to prevent things that are not desirable. So, designers or any other business companies with this sustainable development, should design comfortable pads for the garments and place the pads in strategic and precise locations. That means the kids will avoid getting small bumps. Related to having a sensory integration disorder, in order to create functional clothing, designers have to focus on the material, details, and trims that will be used for garment production. This type of functional clothing design can intermix with other disciplines such as medicine, biotechnology, physics, computing, and others. Functional clothing was developed to improve the quality of life for people with autism that have significantly different mobility and capabilities from a normal person. This study has shown that autistic children are sensitive to the clothing they wear.

Thus, there is a need to design clothing specifically created based on their requirements. The design considerations have to include the motoric limitations, psychological aspects, and social needs [5] Kiddie Pal brand concept created in 2015. It focuses on a clothing collection for autistic children. Kiddie Pal creates fashion collections [6] that are suitable for children 
with autism, so that they can dress more easily and independently. Cotton fabric is tested for Kiddie Pal clothing. The clothing specially designed for autistic children must allow more freedom, independence, safety, and comfort when being worn, but it also has tobe updated, especially related to children's characteristics interms of the product.

\section{LITERATURE REVIEW}

Data was collected from qualitative research done through in-depth interviews. The research was conducted by doing interviews to find in-depth final results. Interviewers are parents whom had children with autism between the age so 6 and 12 years. Total was 11 interviewers. The target market was for older people aged 30-45 years in the middle and upper-class market in Jakarta. Interviews were also conducted with autism therapists from autism institutions in Jakarta, a child psychiatrist, and one teacher from an autism school in Jakarta. The first question asked to the parents was about thei rpersonal experiences of dealing with their children every day, what kinds of daily activities they did, wha tkind sof clothes they wore fo reach activity, and their expectations for appropriate clothing needed for autistic children. Parents are asked to share their experiences in shopping for their child, what is bothering them all this time indressing, where they shop for their favorite clothes, and what they want in the outfit. Interviews were also conducted with four autism therapists from autism institutions in Jakarta, a child psychiatrist, and one teacher from an autism school in Jakarta.

Thirty questions were asked to experts such as therapists and psychiatrists who have studied in the field of autism for many years. Some of the questions were about the difficulty in dealing with children with autism in general, what kinds of therapy autistic children need to have, and other questions specifically related to clothing. Data was also collected through observations at the YPAC (Yayasan Penderita Anak Cacat-Disabled Children's Foundation) in Jakarta to see the behavior of the majority of autistic children and observe how they use clothes and the activities they perform. Based on the observation, mostly autistic children like to wear shorts and short-sleeved shirts.

Meanwhile, apparel with texture materials such as jeans and collared shirts are less favorable. Zippers, buttons, and labels are not necessary and annoyed all of them. So far, the parents bought their kids clothing brands such as Uniqlo, Ginger Snap, and local brands in department stores. Prices ranged from Rp.70,000 until Rp.200,000. Normally, autistic children will pick the clothes by themselves and will touch the cloth first, and if it's thick or rough they will not wear it. In terms of design, some like characters such as, Barney, Dora, Baby Einstein. Parents also advised to use darker colors and waterproof materials. A therapist said that the children also liked the color blue but did not mind any bright or dark color and suggested to avoid using unnecessary details such as beads. The therapist also said it is better for autistic children to wear loose-fit clothing with soft fabric because some of them love the hugging sensation. 

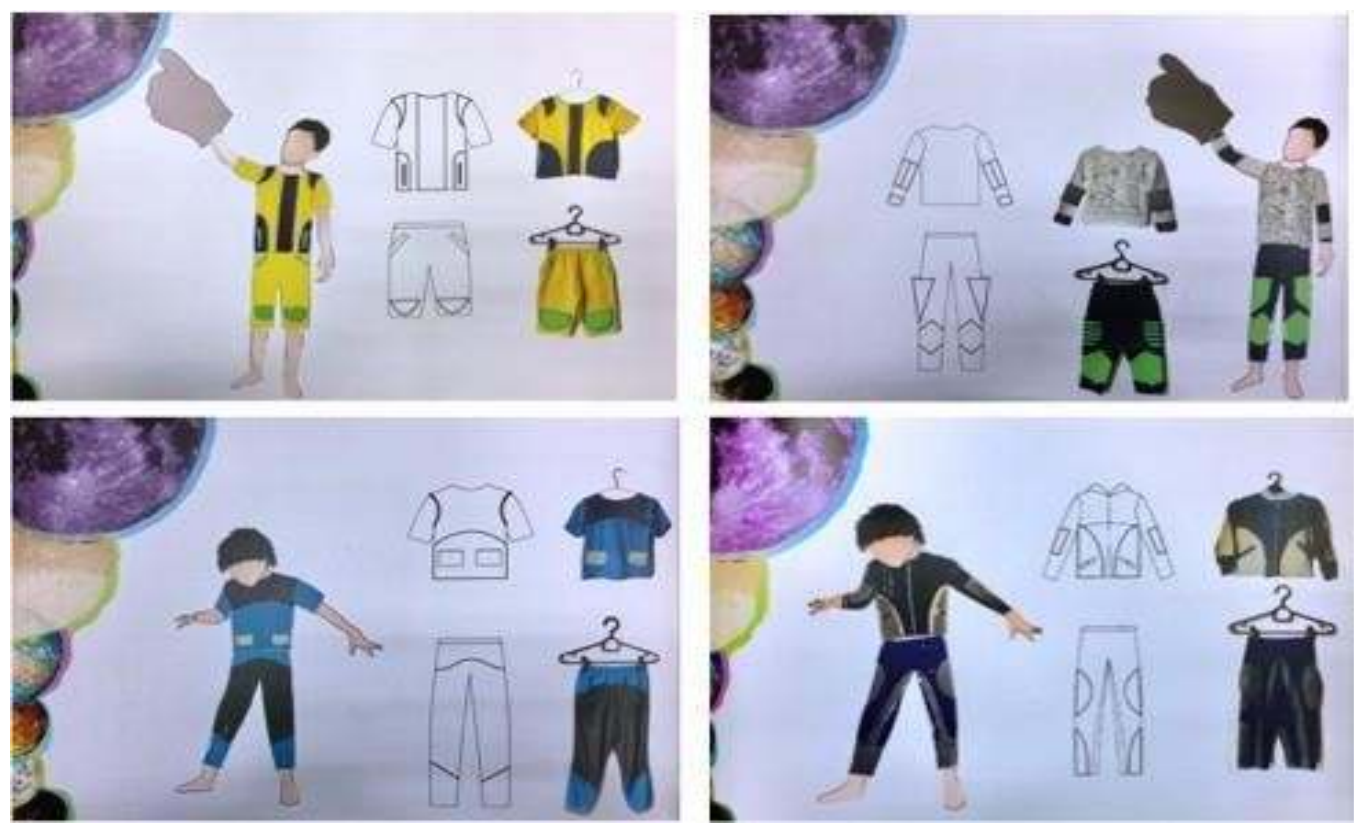

Figure 1. Sketches of designs created by Kiddie Pal

Source: Kiddie Pal Look Book, February 2015
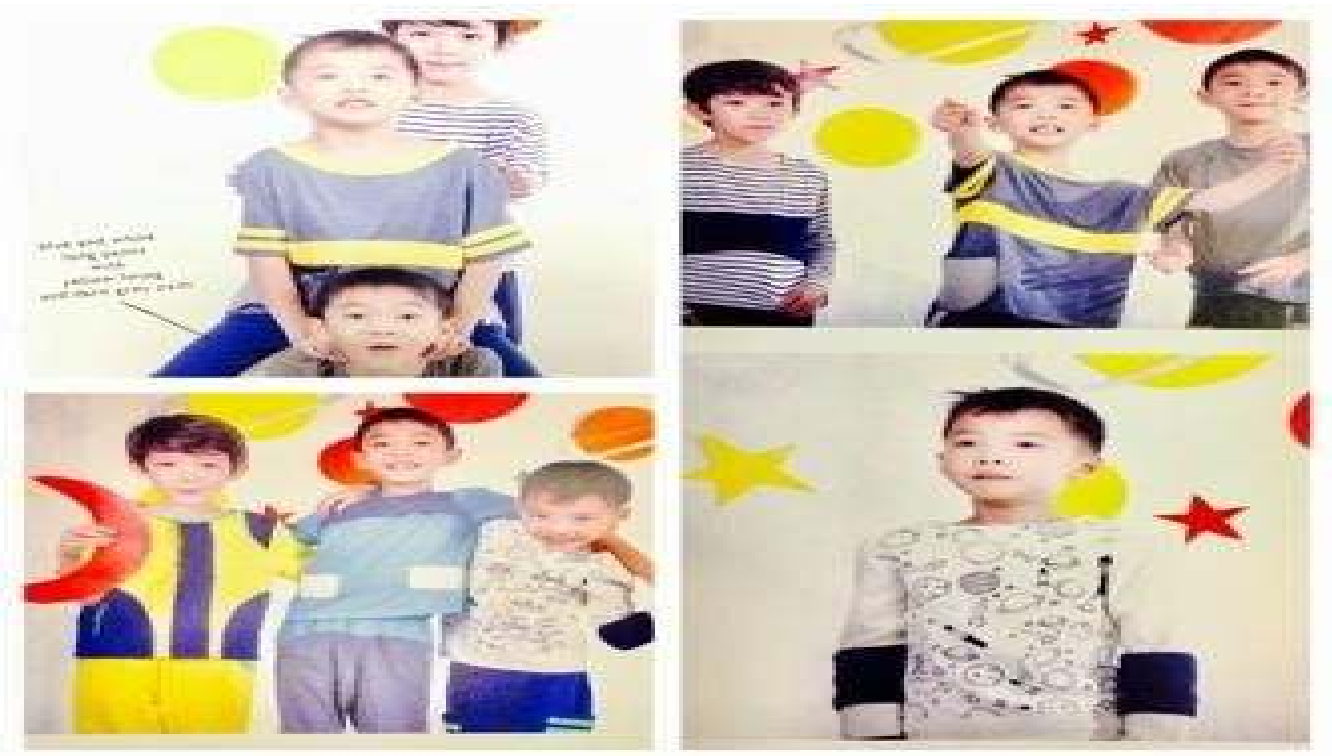

Figure 2. Kiddie Pal first collection in 2015 with the theme "Space." 


\section{RESULTS}

An analysis was conducted of existing products required for children with autism in the process of observing the Kiddie Pal products. In Figure3., several components were divided into the determining factors in the research process. In general, the contextual aspects were based on the needs, wills, and fears of children with autism. They were divided according to the influence of clothing on a human.

For the human factors, the research differentiated between physical and psychological aspects, and a comparison was done based on theories and observations. The results provide recommendations for implementations that can be done in the process of manufacturing of garments for autistic children. In the clothing factor, some elements were studied and analyzed. So, the recommendations can be used for the implementation of the design, wear duration, materials, details, patterns, functions, and colors. When designing clothing for children with autism, the study focused on satisfying their need sat the physical, social, and psychological levels. Therefore, a number of aspects need to be considered, such as the design, color, style, opening of clothes, details, and fabric to be used. Clothing designs for autistic children require a combination of the above components.

\section{DISCUSSION}

The results show that every child with autism has different characteristics, and each individual is special. Put-on and take-off clothes require a lot of patience. Parents expect to have functional clothes sold in the market to help them simplify the process and provide comfort for their children. One of the most common problems is they struggle to put on and take off their clothes. They need someone to help them in the wearing process. They have difficulties in opening and closing buttons, zippers, and other accessories that use a rope. Children with autism are also unaware of the front and back of clothing. They do not care for any additional details that are unnecessary for them such as embroidery, patches, beads, and others.

Overall, an autistic child requires special care for their social community. Autistic children not only need help to get dressed but also need guidance in wearing clothes that are easy to wear and make them more independent. This research also compared the Kiddie Pal collection with other normal children's wear collections and found that autistic children's clothing in terms of designs, colors, and trends is not different from other normal children. From the interviews, it is recommended to choose simpler designs with minimalist decorations, as well as a method without seams (seamless) to make movement easier and avoid itchiness in stitched clothes.

The preferred fabric is cotton, which can also contain elastic to add to the convenience while on the move. It is advisable to use waist band elastic pants for ease in wear and comfort. There should not be any brand label on the back that can make it un comfortable for children. It can be replaced with screen-printing techniques and affixed to clothing to strengthen brand identity. Another research finding is that in Indonesia not everyone is aware of autism, and some parents are not open-minded in sharing their problems in dealing with autistic children. But now parent groups are increasing that aim to socialize awareness about autism in 
Indonesia. Through simplicity in designs, seamless material, and simple trims, it can also reduce production costs and lower selling prices.

\begin{tabular}{|c|c|c|c|c|}
\hline \begin{tabular}{|c|}
$\begin{array}{c}\text { Implementation connected } \\
\text { to the object that will be } \\
\text { designed }\end{array}$ \\
\end{tabular} & Theoritical findings & $\begin{array}{c}\text { General aspects in context } \\
\text { based on need,will,fear } \\
\text { autistic children }\end{array}$ & Observation & $\begin{array}{c}\text { Implementation connected } \\
\text { to the object that will be } \\
\text { designed }\end{array}$ \\
\hline & & HUMAN & & \\
\hline $\begin{array}{c}\text { Standard guideline for } \\
\text { creating collection for person } \\
\text { with a special needs }\end{array}$ & Human body & Physical & $\begin{array}{c}\text { lack of retailer and designer } \\
\text { created the collection for } \\
\text { autistic children }\end{array}$ & $\begin{array}{l}\text { Special design as per } \\
\text { requirement of autistic } \\
\text { children }\end{array}$ \\
\hline \multirow[t]{2}{*}{$\begin{array}{l}\text { Design variation based on } \\
\text { autistic children needs }\end{array}$} & $\begin{array}{l}\text { Mental and education } \\
\text { development }\end{array}$ & Psychological & $\begin{array}{c}\text { parents have difficulties in } \\
\text { wearing cloth for their } \\
\text { autistic children }\end{array}$ & $\begin{array}{c}\text { Easy used clothing for } \\
\text { parents and autistic children }\end{array}$ \\
\hline & & CLOTHING & & \\
\hline $\begin{array}{l}\text { Special design to get the } \\
\text { fastest way in using cloth }\end{array}$ & $\begin{array}{l}\text { Slow process and put in and } \\
\text { take out the cloth }\end{array}$ & Duration of wearing time & $\begin{array}{c}\text { Normal children cloth can be } \\
\text { worn in a longer time } \\
\text { duration }\end{array}$ & $\begin{array}{c}\text { Easy and fast put in and off } \\
\text { on the garment }\end{array}$ \\
\hline $\begin{array}{c}\text { Updated design collection } \\
\text { for clothing }\end{array}$ & $\begin{array}{l}\text { International fashion trend } \\
\text { for children wear }\end{array}$ & Design & $\begin{array}{c}\text { No specifc integration } \\
\text { sensory builed up for a } \\
\text { normal collection }\end{array}$ & $\begin{array}{c}\text { Adding sensory integration } \\
\text { detail on clothing }\end{array}$ \\
\hline $\begin{array}{l}\text { Guideline for fabric that is } \\
\text { suitable for the autistic } \\
\text { children }\end{array}$ & Fabric and materials theory & Material & $\begin{array}{c}\text { No specific materials being } \\
\text { used }\end{array}$ & $\begin{array}{c}\text { Comfortable material that } \\
\text { can support all activites } \\
\text { autistic children }\end{array}$ \\
\hline \begin{tabular}{|c|}
$\begin{array}{c}\text { Guideline of the use of the } \\
\text { right details }\end{array}$ \\
\end{tabular} & Garment construction theory & Garment details & $\begin{array}{c}\begin{array}{c}\text { Less attention on the ouse of } \\
\text { details }\end{array} \\
\end{array}$ & $\begin{array}{l}\text { Focus on the use of the } \\
\text { details in clothing }\end{array}$ \\
\hline $\begin{array}{l}\text { Specific pattem for the } \\
\text { children }\end{array}$ & Pattern making & Pattern & $\begin{array}{c}\text { No specific pattern being } \\
\text { used }\end{array}$ & $\begin{array}{l}\text { Seamless pattern can be } \\
\text { considered in the clothing }\end{array}$ \\
\hline $\begin{array}{l}\text { Clothing design with the } \\
\text { multifunctional concept }\end{array}$ & Functional definition & Functional & $\begin{array}{c}\text { Very limited functional being } \\
\text { used in the clothing }\end{array}$ & $\begin{array}{l}\text { Adding more functional in } \\
\text { the design }\end{array}$ \\
\hline \begin{tabular}{|c|}
$\begin{array}{c}\text { Guideline used based on the } \\
\text { color theory }\end{array}$ \\
\end{tabular} & Color theory & Color & No specific color being used & $\begin{array}{l}\text { Specific colors will be } \\
\text { applied }\end{array}$ \\
\hline
\end{tabular}

Figure 3. An Analysis of The Existing Clothing Products for Autistic Children and Implementation Possibilities.

\section{CONCLUSIONS}

A general direction of the fashion element in manufacturing clothes for autistic children focuses on the particular need soft he children wearing the mand in achieving higher standards, from the point of view of safety, functionality, comfort, psychological aspect, and social aspect. To meet the special requirements of autistic children, different types of clothes might be used, consisting of fabrics with special characteristics such as cotton, cotton with elastic material, and waterproof daily wear out fits.

Theoptimizedselectionofthetextileandclothingassemblycanguaranteetheneededfunctions, protect the body, and make the children feel more comfortable. Their special needs for clothing designs are critical to their quality of life and, at the same time, to their presence in the community. There search survey reveals that the clothing collection concept for autistic children has the potential to develop in the market to fulfill their needs. This study encourages improvements from common usage to more practical and innovative designs. It was found that some necessary details could be deleted to ease the process of dressing and the comfort for the users. The needs of autistic children are special and different.

Thus, there is a need to design clothing specifically created for their requirements. The design considerations have to include the motoric limitations, psychological aspects, and 
social needs. By knowing all the factors influence the manufacturing process, the sustainable business Kiddie Pal brand will be able to continue and development in the community.

\section{REFERENCES}

[1] Autism Science Foundation, "What is Autism?," Autism Science Foundation, 2018. [Online]. Available: https://autismsciencefoundation.org/what-is-autism/.

[2] B. Miller, "Autism Affects Motor Skills Study Indicates," The Source, 2012. [Online]. Available: $\quad$ https://source.wustl.edu/2012/02/autism-affects-motor-skills-studyindicates/.

[3] The National Autistic Society, "About autism," The National Autistic Society, 2018. [Online]. Available: https://www.autism.org.uk/about.aspx.

[4] M. Fattig, "Teaching Organizational Skills - ADHD," Disabled World, 2017. [Online]. Available: $\quad$ https://www.disabled-world.com/health/neurology/adhdautism/organization.php.

[5] G. Pullin, Design Meets Disability. Cambridge: The MIT Press, 2011.

[6] J. A. Ayres, Sensory Integration and the Child. Los Angeles: Western Psychological Service, 2005. 